Punch, S. (2016) 'Cross-world and Cross-disciplinary Dialogue: A More Integrated, Global Approach to Childhood Studies', Global Studies of Childhood, 6 (3).

\title{
Cross-world and Cross-disciplinary Dialogue: A More Integrated, Global Approach to Childhood Studies
}

\author{
Samantha Punch \\ School of Applied Social Science \\ University of Stirling \\ Stirling, FK9 4LA, UK \\ Email: s.v.punch@stir.ac.uk
}

\section{Brief biography:}

Samantha Punch is a Professor of Sociology in the School of Applied Social Science at the University of Stirling, Scotland, UK. Her research and teaching interests are within the sociology of childhood and the sociology of development, including research on children's work and education in Bolivia; the sustainable use of aquatic resources and rural livelihoods in China, Vietnam and India; food practices in residential childcare in the UK; young livelihoods and migration in Latin America; sibling relationships; young people's problems and coping strategies in Scotland.

\begin{abstract}
This paper, by drawing on examples from sociology, anthropology and geography, argues that childhood studies is generally a multi-disciplinary field rather than inter-disciplinary. It emphasises that childhood studies could benefit from greater dialogue between its sub-disciplines as well as with those outside academia. Whilst advances have been made, there is a persistent gap/tension between the discourse of childhood studies and arenas of practice and policy. More effective dialogue could also enhance learning across the Majority and Minority Worlds. Whilst recognising the limitations and challenges of cross-world dialogue, the paper suggests some areas of commonalities and difference between childhoods in the Majority and Minority World as avenues for further empirical and theoretical exploration. The increasingly blurred boundaries across different world areas and across subfields highlights the need for more inter-disciplinary, crossworld dialogue which also bridges the divide between academia and practice.
\end{abstract}

\section{Introduction}

After two decades of establishing children's lives as a topic worthy of study in their own right (James and Prout, 1990), childhood studies has clearly reached a point of scrutiny. Within the UK, there have been many recent discussions of some of the potential problems, including concerns that the theoretical debates of childhood studies have become a little stuck, with a discourse which still struggles to be fully integrated within policy and practice as well as within mainstream academia (for example, Holloway and Pimlott-Wilson, 2011; Horton and Kraftl, 2006; James, 2007; James, 2010; Tisdall and Punch, 2012; Vanderbeck, 2008). This paper contributes to these debates by arguing that one of the key problems of childhood studies has been a lack of dialogue at a variety of levels. In the past two decades, there has been a wealth of empirical material which has emerged within each sub-discipline of childhood studies but without much inter-disciplinary dialogue. Despite many positive moves forward, there continues to be a gap between the academic discourse of childhood studies and arenas of policy and practice. Furthermore, studies of childhoods in the Minority World have tended not to draw on literature involving Majority World childhoods. 
The terms 'Majority World' and 'Minority World' (see also Panelli et al., 2007) are used to refer to what has previously been known as 'the third world' and 'the first world' or more recently as 'the Global South' and 'the Global North'. This acknowledges that the 'majority' of population, poverty, land mass and lifestyles is located in Africa, Asia and Latin America (ie. the Majority World), whilst also encourages us to question unequal global power relations where 'western' and 'northern' populations and issues tend to be privileged despite being the minority (Punch 2003). As with any other global terms, the dichotomy does risk over-homogenising different parts of the world and some countries such as Brazil, China and India do not fit easily within either category. Nevertheless, the dichotomy is a useful lens to challenge thinking within childhood studies, particularly given that the two literatures have separately emerged rather than benefiting from learning across cultural contexts (Punch and Tisdall, 2012). Through an exploration of some of the sociological, geographical and anthropological literature, this paper proposes that it is timely for childhood studies to increase communication and bridge the gaps between its subfields, between academia and practice, and between the Majority and Minority Worlds.

Holt (2011) refers to children's geographies as a sub-interdiscipline to reflect that it is both a subdiscipline as well as an inter-disciplinary field of studies. However, on closer inspection most research in children's geographies, like that of childhood studies, is based on one dominant discipline rather than being inter-disciplinary (see also Alanen 2012). Despite the multi-disciplinary nature of academic childhood journals, children's geographers are more likely to publish in 'Children's Geographies' or 'Children, Youth and Environments' whereas sociologists of childhood tend to publish more frequently in 'Childhood' or 'Children \& Society'. Whilst this is not necessarily problematic nor surprising, what is more disappointing is that each sub-discipline has a tendency to cross-reference work within its own sub-discipline rather than drawing on the broader literature from other disciplines within childhood studies. Thus childhood studies is for the most part multi-disciplinary rather than inter-disciplinary resulting in one of its key strengths being under-utilised (see also Thorne 2007).

This has also led to separate discussions about similar issues, such as amongst sociologists in the Children and Childhood Research Network within the European Sociological Association and between geographers at the Geographies of Children, Youth and Families Research Group (GCYFRG) within the Royal Geographical Society in the UK. Whilst childhood studies allegedly brings the two together, in practice this does not often happen either face-to-face (an exception is the University of Sheffield bi-annual international conference in July) or in bringing the two literatures together on paper. At GCYFRG meetings children's geographers have suggested that they are more likely to cross-reference work from the sociology of childhood but imply that this tends not to be reciprocated.

However, the limited dialogue between the two groups is to some extent mutual (for exceptions, see Holt and Holloway, 2006; Sporton et al., 2006). For example, Kesby et al.'s (2006) paper on theorising 'other childhoods' draws principally on the work of other geographers such as Stuart Aitken and Elsbeth Robson rather than referring more widely to the work of sociologists or anthropologists in the field (for example, Ennew, 2005; Hart, 2006). Thus at times parallel debates are emerging in each sub-discipline with limited communication between them which could be mutually beneficial. Furthermore, Thorne (2007, p.150) calls for the need for 'more fruitful dialogue with the well-established, better funded and much more hegemonic approaches of developmental psychology'.

Whilst inter-disciplinary dialogue may be an ideal, it is worth acknowledging the many barriers and challenges which inhibit sub-disciplinary groupings from working effectively together. Practical constraints include time and language. Each sub-discipline of childhood studies uses a particular theoretical and conceptual language, and we become comfortable with drawing on certain bodies of 
theory or become familiar with particular areas of empirical work. It is very time-consuming to learn to adapt to another discipline and modify one's way of working in order to accommodate a different disciplinary perspective (Sugden and Punch, 2014). The structural context of academia does not readily allow for the time and money required to engage effectively with other disciplines. For example, most academics within the UK are constrained by financial budgets and time which limits the opportunities to attend a range of multi-disciplinary conferences or seminars, or read widely across different disciplines. Thus, despite the drive for funding applications to be increasingly inter-disciplinary, in practice many projects struggle to work effectively across disciplinary boundaries, particularly when the disciplines are very different. However, it might be argued that some of the sub-disciplines of childhood studies, such as geography, sociology and anthropology, are not so distinct and encompass areas of overlap thus making it more possible to talk across disciplinary boundaries. Whilst recognising that childhood studies incorporates a range of disciplines including history, education, psychology, literature and economics, this paper focuses on literature and examples from geography, sociology and anthropology in order to show that even social science disciplines with potential areas of overlap tend not to move beyond disciplinary boundaries.

The recent title of Adrian James' (2010) paper is appropriate here: “Competition or Integration? The next step in childhood studies?" His arguments calling for more integration could certainly be beneficial when considering the separate but related sub-disciplines of childhood studies. Childhood studies perhaps should strive to avoid sub-disciplinary competition between the different fields. Furthermore, the sociologists of childhood (Alanen, 2012), children's geographers (Vanderbeck, 2008) and the anthropologists of childhood (Bluebong-Langner and Korbin, 2007) all struggle with mainstreaming age within their key disciplines, as the childhood sub-disciplines have been traditionally marginalised in study groups and specialist journals. For example, recently two papers on intergenerational relationships by children's geographers have called for a more relational geographies of age (Hopkins and Pain, 2007; Vanderbeck, 2007). Whilst their key concern is to encourage children's geographies to be more integrated within the main discipline of geography, it is a shame that neither of them strengthen their arguments by using the work of childhood sociologists on the relationality of age and the generational order (Alanen and Mayall, 2001).

Holloway and Pimlott-Wilson (2011) also comment that it is still a major challenge for children's geographers to reach outside the sub-disciplinary field. Anthropologists similarly struggle to integrate the anthropology of childhood within anthropology (Bluebond-Langner and Korbin, 2007; Montgomery, 2009). Perhaps if the sub-disciplines of childhood studies communicated more with each other, this might enable key arguments around childhood and age to be more mainstreamed within academia? An excellent example of effective dialogue between a sub-discipline and a main discipline, and between subfields within childhood studies is Vanderbeck's (2008) article critiquing the lack of internal theoretical scrutiny within children's geographies. The focus of the paper is the subfield of children's geographies and its status within the wider discipline of geography. The work is published in the mainstream geography journal Area, and he draws on debates from the sociology of childhood as well as within children's geographies. He also recognises the continued gap between the theoretical assumptions of childhood studies' researchers and the views of practitioners working directly with children.

This paper continues by considering the challenges which lead to the tensions between academia, policy and practice. The difficulties of effective communication are subsequently explored by comparing some of the theories and empirical work of Majority World childhoods with some of those of the Minority World. The paper ends by highlighting some concepts and empirical issues which offer avenues for greater cross-world and inter-disciplinary dialogue within childhood studies. 


\section{Tensions between Childhood Studies and Arenas of Practice and Policy}

Whilst there have been many positive initiatives to promote children's rights and recognise children's agency, as Mayall points out, there is still much to be done because "raising the social and political status of childhood will take a long time" (2006, p.14). James suggests that although academics within childhood studies now take children's voices seriously:

... the need to listen to children's voices is... often paid lip service outside the academy, all too often those voices are silenced by images of childhood that cling to the more traditional, developmental discourse of children's incompetence, rather than competence, as social actors. (James, 2007, p.266)

Too many practitioners and organisations still over-rely on traditional developmental models of understanding childhood in their everyday work (James, 2005; Mayall, 2006). Lansdown and Damsted (2009) argue that this is partly due to the lack of training on children's rights and how to effectively listen to children. They stress the need for child rights education, based on the continuing demands of the Convention on the Rights of the Child, and suggest that unless this happens, attitudes towards, and treatment of, children in accordance with their rights will not change. NGOs and organisations working directly with children may embrace children's rights and the notion of children as social actors, but others, whose field is not specific to childhood, do not readily engage with such ideas.

Furthermore, Vanderbeck (2008) suggests that even practitioners who work directly with children do not necessarily have views which coincide fully with the academic discourses of childhood studies. He implies that this is possibly more of a problem with the language and concepts of childhood studies rather than a lack of understanding or willingness to embrace ideas on the part of practitioners. Perhaps practitioners and policy-makers are not whole heartedly taking on board the notion of children as competent social actors because the language is not nuanced enough (see Tisdall and Punch, 2012). Childhood studies now takes for granted that children are social actors, but recently it has been recognised that this needs to be problematized in relation to wider structures and power relations (see also Bluebond-Langner and Korbin, 2007; Bordonaro and Payne, 2012; Holt and Holloway, 2006) as well as being located within the generational order (Mayall, 2002). For example, Pells (2012) shows how policy makers and practitioners tend to continue to view children as vulnerable, passive and in need of adult protection rather than active social agents despite much evidence to the contrary. In relation to children's geographies, Vanderbeck remarks on this tension:

Although the subfield has repeatedly foregrounded children's competent agency, the theoretical/empirical/political case for maintaining aspects of adult authority is rarely discussed. This is curious because some vision of legitimate age differentiation is almost certainly held by many practitioners. (2008, p.397)

Thus perhaps the time has come for childhood studies to scrutinise its theoretical claims given the ongoing struggles of translating them into practice. Rather than placing blame on policy and practice for not fully realising children's rights or children's agency, perhaps we need to reconsider the ways in which childhood theories are framed. Is it necessary for some of the ambiguities and uncertainties which surround the language, concepts and theories of childhood studies to be unmasked (Vanderbeck, 2008), such as agency, rights and power? For example, the term 'competent social actors' needs to be unpacked for practitioners working with potentially vulnerable children. In practice, it is not necessary clear where the boundaries lie between children's rights to protection and their participation rights as active agents (see Punch et al., 2012). Such ambiguities are not only relevant to complex practice environments since parents, as well as practitioners, may 
question the place of adult power and responsibilities in relation to children's agency (see also Ansell, 2009). Given that many argue that some of the basic concepts of childhood studies have not been mainstreamed in wider society (Lansdown and Damsted, 2009; James, 2007; Mayall, 2006), there may be resistance to toning down the language or recognising the limits or challenges of children's agency. There may be a concern that the political project of children's rights which is so closely aligned with the theoretical underpinnings of childhood studies (King, 2007) may become lost before it has been fully embraced.

Similarly, some have noted that childhood studies has been keen to centre its focus on children and less attention has been given to children within families (Wells, 2009, p.72). As Holt (2011) argues this was partly as a way of striving to assert children as active agents moving away from their more subordinate positioning as family members. The concept of generationing is a useful starting point for considering the different relational categories of adult and child, but it is interesting that it has been relatively under-explored empirically (some exceptions include Alanen and Mayall, 2001; Mayall and Zeiher, 2003; Punch, 2005). For example, what are childing and adulting practices in different contexts and how do we recognise them? As Vanderbeck comments, generationing as a process is appropriate because: "This perspective emphasizes the interplay between structure and agency as individuals and groups negotiate, challenge and (re)construct generational identities and structures" (2007, p.205). In order to fully examine relations and processes of generationing, research needs to incorporate both adults and children's views but this is costly in both time and resources, as well as leading to complexities of how to combine different generational accounts of the same topic (Harden et al., 2010). When intergenerational perspectives have been sought for the same research project, it is surprising that they have not often used this conceptual framework of generationing explicitly.

However, given that the current trend is for funders to be moving towards more inter-disciplinary, large-scale projects (cutting back on small-scale, single disciplinary studies), perhaps it is timely to consider developing more inter-disciplinary, multiple perspective research applications. These might not only incorporate children and parents' or other adults' views, but also the perspectives of practitioners if appropriate. This may also be a sensible strategy given the other new trend towards funding knowledge exchange research and projects that demonstrate 'impact' on the wider community. Hence, the challenge of translating theoretical ideas of childhood studies into practice may be partially addressed by more research collaborations with practitioners. Critical reflection by both professionals and researchers might enhance better communication to extend the bridge over the divide between academic discourse of childhood studies and practice. Another area where communication and learning can be improved within childhood studies itself, is between the literatures which tend to develop separately in Majority and Minority World contexts.

\section{Dialogue between Majority and Minority Worlds}

Adrian James' (2010) call for integration rather than competition in childhood studies refers to the bringing together of the macro and micro understandings of childhood(s). He proposes that a theoretical way forward for childhood studies is to use the metaphor of fabric where the vertical, foundation strands of the warp of the fabric are the more structural issues such as the generational order, gender, class and the social, economic, political and cultural contexts which tend to reflect the commonalities between different childhoods. The horizontal, cross-cutting strands of the weft of the fabric include more micro, situated issues such as children's agency, children's rights and responsibilities, their everyday experiences of education, work and parenting which represent the diversities of children's lives. The two strands weave together creating a particular pattern in the cloth and integrating the perspective of childhood as a singular social category with the diversity perspective of many childhoods (Qvortrup, 2009). 
Thus James' (2010) proposal offers a way of combining the competing approaches to studying childhood(s) without overemphasising the many dichotomies which exist such as child-adult, structure-agency, childhood-childhoods and global-local. He suggests that this fabric framework also allows for both Majority and Minority World childhoods to be explored without implying that some childhoods are more worthy of study than others. However, he does also indicate that most Majority and Minority World childhoods tend to be so different that "a comparison seems unfair and must be resisted" (2010, p.486). Despite some diversity of lifestyles, it has to be acknowledged that most of the Majority World is economically poorer compared with much of the Minority World and that overall levels of income and standards of living are extremely unequal (see Punch et al. 2007). Yet, is it really the case that we can only weave separate cloths for Majority World and Minority World childhoods and that we should not attempt to compare them?

Although direct comparisons of Majority World and Minority World childhoods are rare (Chawla 2002, Katz 2004), there is increasing evidence that global processes can affect children and young people in similar ways (Aitken et al., 2008; Benwell, 2009; Kaufman and Rizzini, 2002; Punch 2014). However, a key danger of attempting global comparisons is to over-homogenise the Majority and Minority Worlds, masking the diversity within and across different countries. It is important to recognise that more effective comparisons between Majority and Minority World childhoods could be made if drawing on samples of children from similar class backgrounds. As Hecht (1998) argues, the nurturing childhoods of the Brazilian poor are likely to have more in common with their working-class counterparts in the Minority World compared with their nurtured middle-class childhoods within their own country.

It is also worth bearing in mind that whilst some international organisations such as Childwatch International or Save the Children conduct empirical studies within the Majority World by researchers from the Majority World, in general most research on Majority World childhoods is carried out by Minority World academics. Partly this is due to limited resources, training and research capacity, including a tendency to focus on natural sciences and on more quantitative rather than qualitative approaches to research (Sugden and Punch, 2014). Another possible reason is that many university degrees in the Majority World have a vocational focus, as well as limited scope at postgraduate level, so there is a comparative lack of sociologists, geographers and anthropologists who would be available to research in the field of childhood studies. It is also likely to be an issue of language and access to publications, as there is a large number of Majority World reports that are published locally and not in English (see Connell, 2007).

Furthermore, whilst childhood studies may have come of age (James, 2007) in the Minority World, this is perhaps not yet the case within academic circles in the Majority World. Minority World researchers who live for prolonged periods in the Majority World in order to research Majority World childhoods (such as Benwell, 2009; Katz, 2004; Montgomery, 2009; Pells, 2012; Punch, 2003) thus are more likely to work with, adapt and critique the theories and concepts developed by Minority World academics. Whilst acknowledging that there is no magic approach and not having the space to discuss here the relative merits and challenges of the roles of insider versus outsider researchers (see Mohammad 2001), it is worth pointing out that there has been a limited amount of indigenous theorising from within the Majority World in relation to childhood studies. As Kesby et al. argue, "there is a need to conceptualise 'other childhoods' as they are and not in terms of what they are not" (2006, p.186). Given the lack of literature which engages in dialogue between the Majority and Minority Worlds, this leads to the following section which suggests some possible areas of similarities and differences which offer avenues for future research in the field of global childhood studies.

\section{Possible Similarities and Contrasts between Majority and Minority World Childhoods}


Some common themes which have been highlighted between Majority and Minority World childhoods are identity, agency and power (Panelli et al., 2007). Using an inter-disciplinary approach can facilitate the process of problematizing such concepts across Majority and Minority World contexts. For example, a key question posed by anthropologists might be the extent to which children's agency tends to be over idealised and whether it is necessarily always positive (see Bluebond-Langer and Korbin, 2007)? This also leads to a potential difference between Majority and Minority World childhoods. Is this ideal of autonomy and freedom of choice imposed by the Minority World on Majority World conceptions of childhood and why is agency so prized? Sociologists might contribute to the debate by unpacking the definition and nature of children's agency (Tisdall and Punch, 2012), perhaps developing a typology of different degrees of agency. Children's geographers are likely to add a spatial dimension and might question whether agency is appropriate in contexts of extreme poverty (see Bordonaro and Payne, 2012)?

Similarly the concepts of power and resistance could benefit from further inter-disciplinary deconstruction. Within intergenerational power relations between children and adults there tends to be an assumption that adult power is negative as adults tend to have too much power over children, whilst children's resistance is likely to be celebrated (Benwell, 2009). Sociologists might scrutinise the relational nature of power imbalances, whilst geographers might ask what are the spatial contexts and arenas when adult power is positive and children's power is negative? Anthropologists might explore when the power differentials are appropriate or even desired (see Punch et al., 2007). Thus this illustrates the contribution that an inter-disciplinary approach can make when striving to move forward the theoretical thinking of childhood studies.

When considering some of the shared challenges that young people face globally, current debates around youth transitions indicate some of the similar consequences of the inequalities of economic globalisation. For example, across both Majority and Minority Worlds youth transitions are fragmented and uncertain, whilst many promises of education are failing (Jeffrey et al., 2008) and youth labour markets are in crisis (Hartas, 2008, p.xix). Informal social networks and interdependent family relations are becoming increasingly important for young people across many Majority and Minority World countries (Punch, 2014). However, a key difference in relation to youth transitions is that they tend to begin much earlier in the Majority World (see Sporton et al., 2006, p.207). There are huge variations of when childhood stops and adulthood begins, and societal expectations of what is appropriate at different stages of the life course also depend on cultural contexts. This can also mean that what is perceived to be a social problem in one part of the world, such as teenage pregnancy, is not considered problematic elsewhere.

Other social problems, such as the fear of youth in local areas and on the street can be similar across the Majority and Minority Worlds. Wells (2009) suggests that even the term 'youth' has negative connotations as young people are often perceived as threats (Hartas, 2008, p.6) particularly in relation to being on the streets or committing crime. The increasing intolerance of children in public spaces (Hartas, 2008, p.56) and the adult desire to keep them off the streets in the Minority World echoes concerns for children 'out of place' in the Majority World, such as street children (Ennew, 2005).

A key contrast between many Majority and Minority World childhoods is poverty. More extreme levels of absolute poverty exist in the Majority World (Punch et al., 2007) and the numbers experiencing such poverty are higher. Children in the Minority World are more likely to suffer from relative poverty rather than absolute poverty. Furthermore, whilst globally social inequalities are increasing, huge disparities of wealth exist between the overwhelming majority of poor people and the very small minority of rich people in the Majority World. An obvious difference, related but not exclusive to poverty, is that work tends to be more central to Majority World childhoods (Punch, 2003). This is not to say that Minority World children do not work, but that they are more likely to 
start part-time work later than their Majority World counterparts, and their work is less likely to be full-time and essential for household survival. There is a debate over the extent to which children's work in the Minority World is symbolic (often middle-class parents striving to teach their children the value of money) or whether it is more directly linked to children living in poverty (see Mizen et al., 2001).

The arena of play and leisure may be a possible site of comparison between Majority and Minority World childhoods. McKendrick et al. (2000) have discussed the commercialisation of children's play spaces in the Minority World, where children's social worlds have become more structured, institutionalised and controlled by adults. Are there possibly more opportunities for free, unstructured and unsupervised play in many parts of the Majority World? Children's work roles and household responsibilities are likely to enable them to have higher degrees of spatial autonomy (Punch, 2007). Whilst, on the one hand, their higher levels of household responsibilities may constrain the time available that they have to dedicate to play, on the other hand, it may lead to increased opportunities to play away from the gaze of adults (see for example Katz, 2004). Many Majority World children are likely to have fewer manufactured toys, more limited access to shopping malls and commercialised leisure activities, and therefore perhaps less of a consumer identity. However, this is a class-based issue: rich Majority World children who are chaperoned and often subject to adult surveillance are likely to have much more in common with the shrinking physical spaces of Minority World childhoods (Hartas, 2008, p.65).

There is also a global digital divide which impacts on children's leisure possibilities. For example, the recent increase and use of social networking sites in the Minority World is creating new forms of virtual friendships as well as cases of cyber-bullying (Hartas, 2008). Both the quality and quantity of available computers and internet access in the Majority World mean that social networking sites are likely to be mainly used by the nurtured, richer childhoods of Majority World countries (Hecht, 1998). Similarly, although mobiles phones are becoming more widely used globally, there is still not equal access by any means.

Vanderbeck (2007, p.207) distinguishes between Riley and Riley's age-integrated and agedifferentiated societies which can largely be mapped onto the Majority and Minority worlds respectively. Age integrated societies are not structured rigidly according to age, particularly in the arenas of work and leisure whereas age differentiated societies emphasise the separate social worlds of children and adults. For example, children's sharing of time and space within adult public worlds tends to occur more in the Majority World whereas children's lives in the Minority World tend to be more age-segregated. Also there tends to be less mixing between children of different ages within the Minority World compared with the Majority World. Hartas (2008, p.57) argues that overprotecting children in the Minority World can decrease their opportunities to develop problem solving capacities and resilience. For example, many young children in the Majority World care for their younger siblings; in rural Bolivia girls as young as five years old may be left caring for their younger siblings whilst parents are out working (Punch, 2003) whereas children in the UK are generally not considered responsible to babysit their siblings until they are at least 14 years old.

Another possible distinction is that children's rights have perhaps filtered more into households in the Minority World compared with many parts of the Majority World. Questions which arise here include: are Minority World families more likely to be child-centred and take children's opinions seriously compared with more adult-focused families in the Majority World? Thus, are many children in affluent families potentially more able to assert their agency within the domestic sphere? In what ways are children's rights translated into the different arenas of school, work, play and policy across Majority and Minority Worlds? 
Obviously many of the key contrasts and similarities suggested above are problematic in terms of homogenising Majority and Minority Worlds but the intention has been to suggest possible avenues for further inter-discplinary exploration. Whilst it may not always be appropriate to make direct comparisons between Majority and Minority World childhoods, there are certainly opportunities for learning cross-culturally and for engaging in conversations between cases (Thomson, 2007). Many interesting questions arise, such as, is birth order more important in countries of the Majority World where family size tends to be larger (see Punch, 2001)? Are children's levels of responsibility greater in some parts of the Majority World and, if so, is long-term reciprocity and the persistence of kinship ties (such as emotional and physical care) stronger in these Majority World settings? In what contexts is it necessary to have control over individual lives or are interdependencies more important? Are the notions of generational proximity or the generational order different in Majority and Minority World countries? For example, do children want generational proximity or to embrace the differences between children and adults? The geographical spatialities of intergenerational conflict or compromise could be considered alongside a sociological understanding of care versus control. An anthropological perspective might include the intergenerational negotiations of these in different cultural contexts. Thus, further inter-disciplinary exploration of the concepts of 'generation' and 'generationing' would be useful and facilitate the integration of theoretical thinking across disciplines (Alanen and Mayall, 2001).

\section{The Blurring of Majority/Minority World Boundaries}

This paper has emphasised some of the benefits of using an inter-disciplinary approach to encourage greater reflection and learning in relation to childhoods and intergenerational relations across the world. Whilst risking an overly simplistic dichotomy, it could be said that to some extent households in the Majority World tend to be based on more collectivist values where relations of interdependence are expected across the lifecourse, and children are often responsible for caring for their parents in old age (Murphy-Berman and Kaufman, 2002). Inter- and intra-generational interdependencies and obligations are likely to be more marked in Majority World contexts where there are no or limited welfare benefits (Punch, 2014). In contrast, Minority World cultures are more often based on individualistic values of independence, self-sufficiency, freedom, personal choice and assertiveness. However, Murphy-Berman and Kaufman (2002) argue that new cultural forms are emerging which "both support the development of autonomy and encourage a strong sense of relatedness with others" (2002, p.25). They suggest that social cooperation and commitment are not necessarily incompatible with developing children's independence and autonomy. This perhaps illustrates that there is a blurring of Majority and Minority Worlds (see also Panelli et al., 2007) and that a range of possibilities exist globally.

Global processes and events such as economic migration, global care chains, natural disasters and war, have led to increasing numbers of migrants, refugees and asylum seekers which contribute to the overlapping of boundaries between the Majority and Minority Worlds. Transnational families are developing new ways of living apart and together (Bastia and Busse, 2011; Kaufman and Rizzini, 2002). However there are many unequal impacts of the intersections between different world areas. For example, global care chains tend to involve women in the Minority World subcontracting or outsourcing care work (of children or older people) to women from the Majority World (Hartas, 2008, p.49). Ehrenreich and Hochschild (2003) refer to this as emotional imperialism. Similarly, technology such as the internet and mobile phones may be transforming global communications as well as how children are socialised and how they relate with their peers (Hartas, 2008), but this is also extremely unequal (in terms of access, quality of goods and technological skills) across Majority and Minority Worlds. The study of relationships across borders can add to our broader understandings of intimacy and social networks in a globalising world where people often struggle to achieve an effective work-life balance or strive to maintain relationships across time and space. Hence, this paper has argued that more effective cross-world 
and cross-disciplinary dialogue could increase our understanding of childhoods and intergenerational relations, providing the dialogue is 'sensitive to difference and alive to the global structural processes' (Farrugia 2014: 303) which shape young people’s lives.

This paper began by considering the limited engagement between the separate sub-disciplines of childhood studies and has ended by exploring some of the conceptual and empirical possibilities for more inter-disciplinary dialogue between Majority and Minority Worlds. Three related but distinct sub-disciplines have been discussed in relation to the development of the social studies of childhood: the sociology of childhood, the anthropology of childhood and children's geographies. It has been shown that at times there is a lack of inter-disciplinary dialogue between them as well as with other strands of childhood studies. Each of them struggle, yet strive, to integrate the subdiscipline of childhood more centrally within their main discipline. Furthermore, although each subfield conducts research in both Majority and Minority Worlds, there is a need for more crossworld dialogue as well as combining sub-disciplinary literatures within childhood studies. Childhood studies and age could benefit from being more integrated within academic disciplines rather than remaining on the margins (Alanen, 2012). Similarly, theories and concepts of childhood studies could be better linked to policy and practice within both the Majority and Minority Worlds. Whilst many positive developments have been made, there are still many challenges of translating childhood theories and children's rights into both global and local arenas of policy and practice (Tisdall and Punch, 2012). Thus this paper calls for a more mainstreamed global approach to childhood studies based on inter-disciplinary integration and cross-world dialogue.

\section{References}

Aitken, S., Lund, R. and Kjøholt, A. (eds) (2008) Global Childhoods: Globalization, Development and Young People. London: Routledge.

Alanen, L. (2012) Disciplinarity, Interdisciplinarity and Childhood Studies. Childhood, 19(4), 419422.

Alanen, L. and Mayall, B. (2001) (eds) Conceptualising Child-Adult Relations. London: RoutledgeFalmer.

Ansell, N. (2009) Childhood and the Politics of Scale: Descaling children's geographies? Progress in Human Geography, 33(2), 190-209.

Bastia, T. and Busse, E. (2011) Transnational Migration and Changing Gender Relations in Peruvian and Bolivian Cities. Diversities, 13(1), 19-34.

Bluebond-Langner, M. and Korbin, J. (2007) Challenges and Opportunities in the Anthropology of Childhoods: An Introduction to 'Children, Childhoods, and Childhood studies,' American Anthropologist, 109(2): 241-246.

Bordonaro, L. and Payne, R. (2012) Ambiguous Agency: Critical perspectives on social interventions with children and youth in Africa. Special issue of Children's Geographies, 10(4), 365-372.

Chawla, L. (ed) (2002) Growing Up in an Urbanising World. London: Earthscan Publications.

Connell, R. (2007) Southern Theory: The Global Dynamics of Knowledge in Social Science. 
Cambridge: Polity Press.

Ennew, J. (2005) Prisoners of Childhood: Orphans and economic dependency, in Qvortrup, J. (ed,) Studies in Modern Childhood: Society, Agency and Culture. Basingstoke: Palgrave Macmillan.

Ehrenreich, B. and Hochschild, A. (eds) (2003) Global Women: Nannies Maids and Sex Workers in the New Economy. Basingstoke: Macmillan.

Farrugia, D. (2014) Towards a Spatialised Youth Sociology: The rural and the urban in times of change, Journal of Youth Studies, 17(3), 293-307.

Harden, J., Backett-Milburn, K., Hill, M. and Maclean, A. (2010) Oh what a tangled web we weave: experiences of doing multiple perspectives research in families. International Journal of Social Research Methodology, 13(5), 441-452.

Hart, J. (2006) Saving Children: What role for anthropology? Anthropology Today, 22(1), 5-8.

Hartas, D. (2008) The Right to Childhoods: Critical Perspectives on Rights, Difference and Knowledge in a Transient World. London: Continuum.

Hashim, I. and Thorsen, D. (2011) Child Migration in Africa. London: Zed Books.

Hecht, T. (1998) At Home in the Street: Street Children of Northeast Brazil. Cambridge: Cambridge University Press.

Holt, L. (ed.) (2011) Geographies of Children, Youth and Families: An International Perspective. London: Routledge.

Holt, L. and Holloway, S. (2006) Theorising Other Childhoods in a Globalised World, Children's Geographies, 4: 135-42.

Holloway, S. and Pimlott-Wilson, H. (2011) Geographies of children, youth and families: defining achievements, debating the agenda. In L. Holt (ed) Geographies of Children, Youth and Families: An international perspective. London: Routledge, 9-24.

Hopkins, P.E. and Pain, R. (2007) Geographies of age: thinking relationally, Area 39(3), 287-294.

Horton, J. and Kraftl, P. (2006) What else? Some more ways of thinking and doing 'Children's Geographies,' Children's Geographies, 4, 69-95.

James, A. (2005) Life Times: Children's Perspectives on Age, Agency and Memory across the Life Course, in Qvortrup, J. (ed.) Studies in Modern Childhood: Society, Agency and Culture, Basingstoke: Palgrave Macmillan.

James, A. (2007) Giving Voice to Children's Voices: Practices and problems, pitfalls and potentials. American Anthropologist, 109(2), 261-72.

James, A. (2010) Competition or Integration? The next step in childhood studies? Childhood, 17(4), 485-499.

James, A. and Prout, A. (1990) Constructing and Reconstructing Childhood. London: Falmer. 
Jeffrey, C., Jeffery, P. and Jeffery, R. (2008) Degrees Without Freedom? Education Masculinities and Unemployment in North India. Palo Alto: Stanford University Press.

Kesby, M., Gwanzura-Ottemoller, F. and Chizororo, M. (2006) Theorizing Other, "Other Childhoods": Issues emerging from work on HIV in urban and rural Zimbabwe. Children's Geographies, 4(2), 185-202.

King, M. (2007) The Sociology of Childhood as Scientific Communication: Observations from a social systems perspective, Childhood 14(2): 193-213.

Kaufman, N.H. and Rizzini, I. (2002) (eds) Globalization and Children: Exploring potentials for enhancing opportunities in the lives of children and youth. New York: Kluwer Academic/Plenum Publishers.

Lansdown, G. and Damsted, B. (2009) Promoting Young Children's Rights through the Development of Sustainable Education for Key Professionals, in Bernard van Leer Foundation, Realising the Rights of Young Children: Progress and challenges. Early Childhood Matters, November 2009, 113.

Mayall, B. and Zeiher, H. (2003) (eds) Childhood in Generational Perspective. London: Institute of Education, University of London.

McKendrick, J.H., Bradford, M.G. and Fielder, A.V. (2000) Kid Customer?

Commercialisation of playspace and commodification of childhood. Childhood, 7(3), 295-315.

Mizen, P., Pole, C. and Bolton, A. (eds) (2001) Hidden Hands: International Perspectives on Children's Work and Labour. London: RoutledgeFalmer.

Mohammad, R. (2001) 'Insiders' and/or 'outsiders': Positionality, theory and praxis, in Limb, M. and Dwyer, C.(eds) Qualitative Methodologies for Geographers, London: Arnold, p101120.

Montgomery, H. (2009) An Introduction to Childhood: Anthropological Perspectives on Children's Lives. Chichester: Wiley-Blackwell.

Murphy-Berman, V. and Kaufman, N.H. (2002) Globalization in Cross-Cultural Perspective, in N. Kaufman and I. Rizzini (eds) Globalization and Children: Exploring potentials for enhancing opportunities in the lives of children and youth, New York: Kluwer Academic/Plenum Publishers, pp.19-30.

Panelli, R., Punch, S. and Robson, E. (eds) (2007) Global Perspectives on Rural Childhood and Youth: Young Rural Lives. London: Routledge.

Pells, K. (2012) 'Rights are everything we don't have': Clashing conceptions of vulnerability and agency in the daily lives of Rwandan children and youth, Children's Geographies, 10(4), 427-440.

Punch, S. (2001) Household Division of Labour: Generation, Gender, Age, Birth Order and Sibling Composition, Work, Employment \& Society, 15(4), 803-823.

Punch, S. (2003) Childhoods in the Majority world: Miniature adults or tribal children? Sociology, 37(2), 277-295. 
Punch, S. (2005) The Generationing of Power: A Comparison of Child-Parent and Sibling Relations in Scotland, Sociological Studies of Children and Youth, Volume 10, 169-188.

Punch, S. (2007) Generational Power Relations in Rural Bolivia, in Panelli, R., Punch, S. and Robson, E. (eds) Global Perspectives on Rural Childhood and Youth: Young Rural Lives. London: Routledge, pp.151-164.

Punch, S. (2015) 'Possibilities for Learning between Childhoods and Youth in the Minority and Majority Worlds: Youth transitions as an example of cross-world dialogue,' in Wyn, J. and Cahill, H. (eds) Handbook of Children and Young Adulthood, Singapore: Springer, pp.689-701.

Punch, S., Bell, S., Costello, L. and Panelli, R (2007) Power and Place for Rural Young People, in Panelli, R., Punch, S. and Robson, E. (eds) Global Perspectives on Rural Childhood and Youth: Young Rural Lives. London: Routledge.

Punch, S., McIntosh, I. and Emond, R. (2012) 'You have a right to be nourished and fed, but do I have a right to make sure you eat your food?': Children's Rights and Food Practices in Residential Care', International Journal of Human Rights, 16(8), 1250-1262.

Punch, S. and Tisdall, K. (2012) Exploring Children and Young People's Relationships Across Majority and Minority Worlds, Children's Geographies, 10(3), 241-248.

Qvortrup, J. (2009) Childhood as a Structural Form, in Qvortrup, J., Cosaro, W. and Honig, M. (Eds) The Palgrave Handbook of Childhood Studies. Basingstoke: Palgrave Macmillan, pp.21-33.

Sporton, D., Valentine, G. and Nielsen, K.B. (2006) Post-Conflict Identities: Practices and Affiliations of Somali Asylum Seeker Children, Children's Geographies, 4(2), 203-217.

Sugden, F. and Punch, S. (2014) 'The Challenges and Benefits of Employing a Mobile Research Fellow to Facilitate Team Working on a Large, Interdisciplinary, Multi-sited Project,' Research in Comparative and International Education, 9(4): 441-453.

Thomson, R. (2007) The Qualitative Longitudinal Case History: Practical, methodological and ethical reflections, Social Policy and Society, 6(4), 571-582.

Thorne, B. (2007) Editorial: Crafting the interdisciplinary field of childhood studies, Childhood, 14 (2): 147-152.

Tisdall, K. and Punch, S. (2012) Not so 'new'? Looking Critically at Childhood Studies, Children's Geographies, 10(3), 249-264.

Vanderbeck, R.M. (2007) Intergenerational Geographies: Age relations, segregation and reengagements, Geography Compass, 1(2), 200-221.

Vanderbeck, R. (2008) Reaching Critical Mass? Theory, politics, and the culture of debate in children's geographies, Area, 40(3), 393-400.

Wells, K. (2009) Childhood in Global Perspective. Cambridge: Polity Press. 